\title{
Investigating the relationship between early maladaptive schemes and fear of negative evaluation in students with test anxiety
}

\author{
Elahe Ahangari ${ }^{1}$, Mohammad Tahan ${ }^{2}$, Zahra Syadabadi ${ }^{3}$, Azam Sadeghifar ${ }^{4}$ \\ 1-Lecturer, Department of Psychology and Educational Sciences, Payam Noor University, Tehran, Iran \\ (Corresponding Author). E-mail: Ahangarielahe@gmail.com \\ 2- Lecturer, Young Researchers and Elite Club, Birjand Branch, Islamic Azad University, Birjand, Iran. \\ 3- Lecturer, Department of Psychology, Qaenat Branch, Islamic Azad University, Qaenat, Iran. \\ 4- Lecturer, Department of Psychology, Central Tehran Branch, Islamic Azad University, Tehran, Iran.
}

Received: $31 / 01 / 2020$

Accepted: 04/03/2020

\begin{abstract}
Introduction: Test anxiety is one of the most common psychological problems that plays a destructive and deterrent role in students' mental and educational health, which can impair a person's performance and lead to failure in the exam.

Aim: The present study aimed to investigate the relationship between early maladaptive schemas and fear of negative evaluation in students with test anxiety.

Method: The present study is a correlational correlation. The statistical population of the study included all students with test anxiety who referred to Ghaenat Education Counseling Center in 2018 (100 people). Who were purposefully selected. Subjects responded to the Young Inconsistent Schema Schedule Questionnaire (2005), the Scale Scale of Lieri Negative Assessment (1983). The data collected were analyzed using SPSS software version 25.

Results: The results showed that there is a relationship between early maladaptive schemas and fear of negative evaluation in students with test anxiety. $(\mathrm{P}<0.05)$

Conclusion: The results showed that early maladaptive schemas and fear of negative evaluation play an important role in students' test anxiety. Cultivating successful and healthy students will lead to a healthier and more successful society.
\end{abstract}

Keywords: Eearly maladaptive schemas, Fear of negative evaluation, Test anxiety, Students

How to cite this article : Ahangari E, Tahan M, Syadabadi Z, Sadeghifar A. Investigating the relationship between early maladaptive schemes and fear of negative evaluation in students with test anxiety. Shenakht Journal of Psychology and Psychiatry. $2020 ; 7$ (2): 1-12 .URL: http://shenakht.muk.ac.ir/article-1-636-fa.pdf

Copyright $\odot 2018$ the Author (s). Published by Kurdistan University of Medical Sciences. This is an open access article distributed under the terms of the Creative Commons Attribution-Non Commercial License 4.0 (CCBY-NC), where it is permissible to download, share, remix, transform, and buildup the work provided it is properly cited. The work cannot be used commercially without permission from the journal. 


\title{
بررسى رابطه طرحوارههاى ناساز كار اوليه و ترس از ارزيابى منفى در داشش آموزان مبتلا به اضطراب امتحان
}

\author{
الهه آهنكرى'، محمد طحان"، زهر ا سيد آبادى"، اعظم صادقى فر

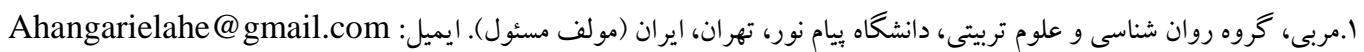

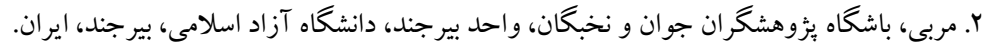

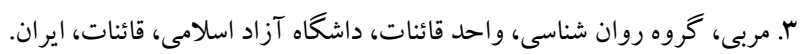

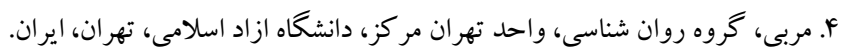

مقدمه: اضطراب امتحان يكى از شايعترين مشكلات روانى كه نقش مخرب و بازدارندهاى در سلامت روانى و آموزشى دانش آموزان

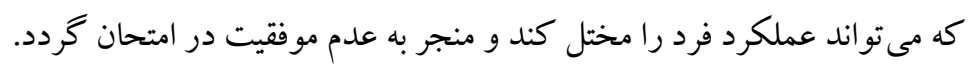
هدف: مطالعه حاضر با هدف بررسى رابطه طرحوارههاى ناساز گار اوليه و ترس از ارزيابى منفى در دانش آموزان مبتلا به اضطراب

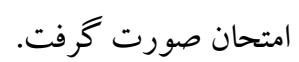

روش: مطالعه حاضر توصيفى از نوع همبستخى است. جامعه آمارى بزوهش شامل كليه دانشآموزانى مبتلا به اضطراب امتحان

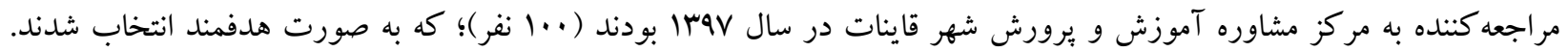

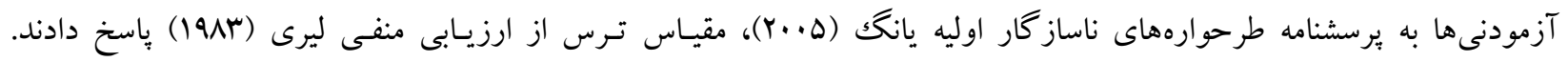

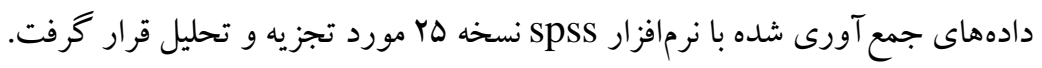
يافتهها: نتايج نشان داد كه بين طرحوارههاى ناساز گار اوليه و ترس از ارزيابى منفى در دانش آموزان مبتلا به اضطراب امتحان رابطه

$$
\text { وجود دارد (P>/· (P). }
$$

نتيجه كيرى: نتايج حاكى از آن بود كه طرحوارههاى ناساز كار اوليه و ترس از ارزيابى منفى، نقش مهمى در اضطراب امتحان

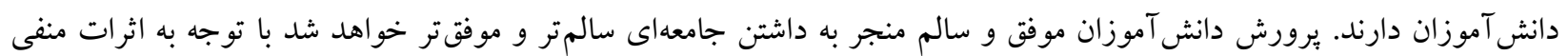

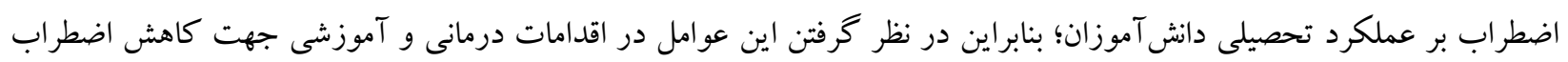
امتحان مىتواند بسيار مؤثر باشد. كليدوازهها: ترس از ارزيابى منفى، طرحوارههاى ناساز كار اوليه، اضطراب امتحان، دانش آموزان 
اضطراب امتحان، اضطرابى است كه در حالت و موقعيت مقدمه

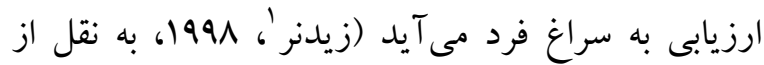

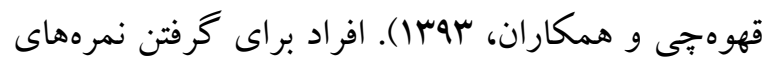
بالا در امتحانات تحتفشار زيادى قرار دارند، بنابراين

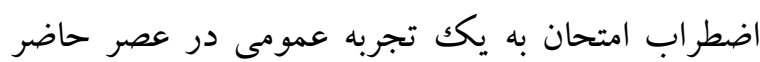

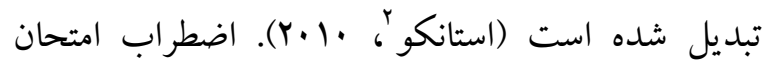

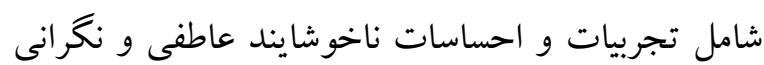
يا تشويش در موقعيتهايى است كه فرد احساس مى كند

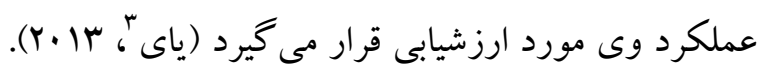

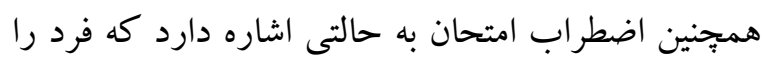

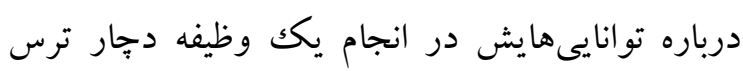
مى كند و ييامد آن كاهش توان مقابله با موقعيت هايى مانند موقعيت امتحان است (فاتحى، عبدخدايى، يورغلامى و ناظمى، بوس1). اضطراب امتحان در محيط

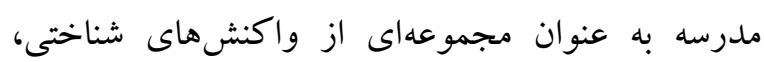

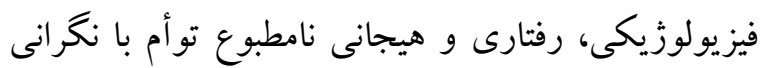
درباره نتايج منفى احتمالى يا انتظار شكست در امتحان يا موقعيتهاى ارزيابى مشابه تعريف شده است (كومر و

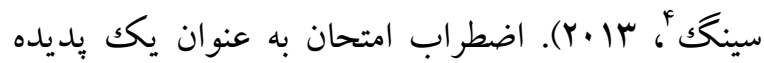
متداول و مهم آموزشى رابطه تنگاتنكى با عملكرد و و ييشرفت تحصيلى كودكان و نوجوانان دارد (بكك و و

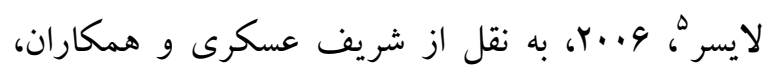

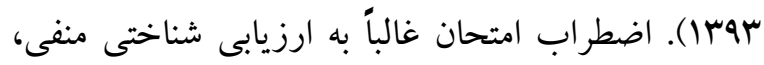
واكنشهاى فيزيولوزيكى نامطلوب و افت عملكرد تحصيلى منجر مى شود و به همين دليل در سلامت روانى

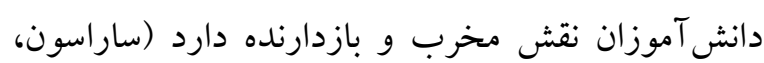

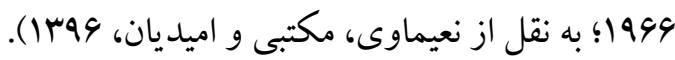

1- Zeidner

2- Stankov

3 - Yee

4- Kumar \& Singh

5 - Blake \& Lesser
امروزه امتحان به بخشى ذاتى از زندگى افراد تبديل شده است. بسيارى از تصميم گيرىهاى مهم به واسطه نتايج آزمون اتخاذ مىشود؛ بنابراين تعجب آور نيست كه اضطراب در حين امتحان يك مشكل برجسته در سراسر جهان به شمار آيد (تريفونى و شاهينى، I| (Y). اضطراب امتحان به عنوان يك بِ بديده متداول سالانه ميليونها دانش آموز و دانشجو را در سراسر جهان تحت تأثير قرار

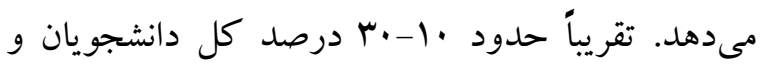
دانش آموزان از اين نوع اضطراب كه به اضطراب امتحان ناتوان كننده نيز شهرت دارد، رنج مىبرند. اين پِديده شايع، از جمله مشكلات جدى محيطهاى آموزشى و از

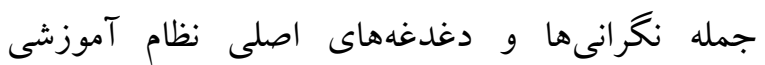
محسوب مىشود (درتاج و همكاران، بوبr). يكى از گستردهترين قلمروهاى تحقيق در جند دهه اخير، اضطراب و حوزههاى وابسته به آن بوده است (ايزدى نيا و قنبرى، 94سا). اضطراب مفهوم نآشنايى نيست. اين مفهوم از جمله احساساتى است كه همانند ترس هميشه همزاد بشر بوده است و در تئورىهاى مختلف روانشناسى، از آن به عنوان ريشه مشكلات نامبرده شده است. كمتر انسانى را مىتوان يافت كه در طول زندگى روتى خود با اين مسئله مواجه نشده باشد. اغراق نيست اكر كفته شود همه انسانها در همه اعصار و با هر فرهنگى آن را

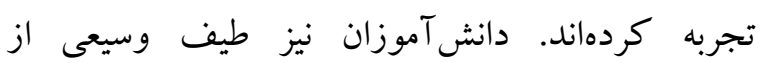
اضطر ابها را تجربه مى كنند. اين اضطرابها كاه از جنان شدتى برخوردارند كه زندگى روزمره و تحصيلى آنان را دشوار مىسازد و يكى از اصلى ترين انواع اين اضطرابها، اضطراب امتحان است (درتاج، موسوى و رضايى، . (Irar 
شديد مرتبط با موقعيـتهـاى اجتمـاعى مـؤثر است (ريسى و هيمبر گك'، 199V، به نقل قاسم بور و فلاح، سوس ا).

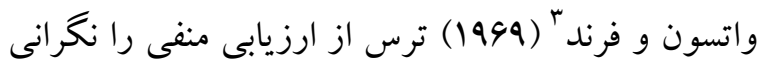

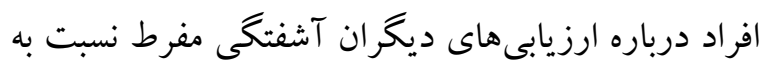
ارزيابىهـاى منفـى، اجتنـاب از موقعيـتهـاى ارزيـابى و انتظار تجربـه ارزيـابىهـاى منفىى از سـوى ديخـران، تعريـف كردنـد. سازه ترس از ارزيابى منفى شامل

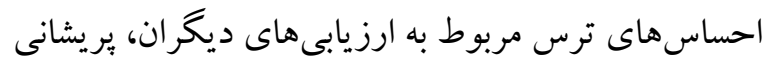
خاطر ناشى از اين ارزيابىهاى منفى و انتظار اينكه ديخران او را منفى ارزيابى خواهد كرد مىشود (حميد، حسينزاده و كيانىمقدم، أو (I). ترس از ارزيابى منفى و خود ارزيابى ضعيف موجب اجتناب از موقعيتهاى

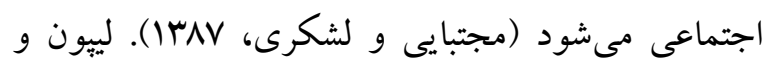

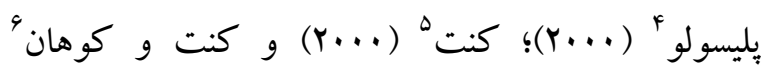
نيز نشان دادهاند افرادى كه به اضطراب مبتلا هستند، خودشان را نسبت به ارزيابى منفى از جانب

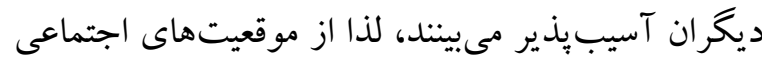
(مانند امتحان) مى ترسند. آنها فكر مى كنند كه ديخران در حال نظارت، وارسى و ارزيابى منفى از جنبههاى مختلف رفتار، عملكرد و ظاهر آنها هستند. ترس شديد از ارزيابى منفى توسط ديخران، منجر به بروز نارضايتى و

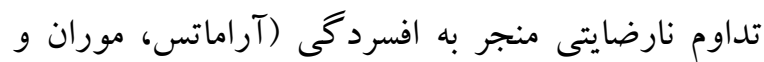

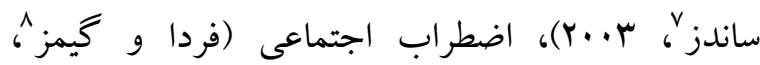

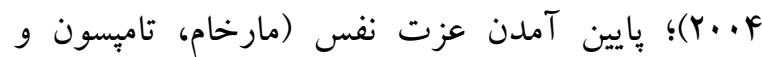

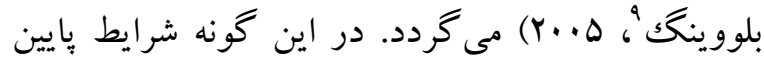

\footnotetext{
2- Rapee \& Heimberg

3 - Watson \& Friend

${ }^{4}$ - Lepine, \& Pelissolo

5 - Kent

6- Kent \& Keohan

7. Aramats, Moran \& Sands

8 - Freda \& Gamze

9. Markham, Thompson \& Blowing
}

طرحوارههاى ناساز گار به عنوان زيرساختهاى شناختى منجر به تشكيل باورهاى غير منطقى مىشود. طرحوارهها داراى مؤلفهاى شناختى، عاطفى و رفتارى هستند

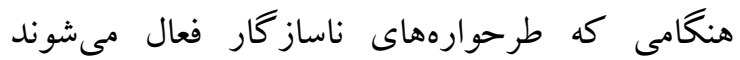
سطوحى از هيجان منتشر مىشود و مستقيم يا غير مستقيم منجر به اشكال مختلفى از آشفتكىهاى روان

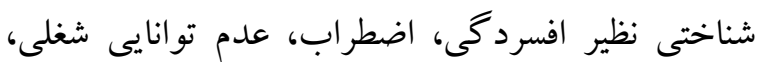
تعارضات بين فردى و مانند آن مىشود. طرحوارههاى ناساز كار مستقيماً منجر به اختلال خاصى نمى مُوند؛ اما آسيب بذيرى فرد را براى اين اختلال افزايش مىدهند

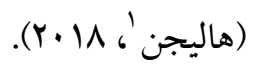
يكى از عوامل اضطراب امتحان طرحوارههاى ناساز گار

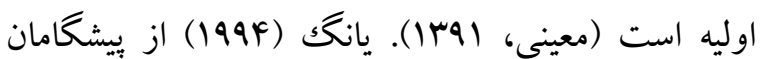
رويكرد طرحواره محور، معتقد است همانطور كه طرحوارههاى ناساز كار اوليه در اختلالات شخصيت فعال مىشود در هنگام موقعيتهاى اضطرابى و افسردگى نيز فعال خواهند شد. بك (19V9) نيز بيان مى كند كه عواطف و رفتارهاى ما به وسيله طرحوارههاى شناختى ايجاد مى شود و بر روى ادراكك ما از دنيا تأثير مى كذارند. در واقع همانطور كه سيستم قلبى و عروقى براى كاركرد بدن انسان مهم و ضرورى است، طرحوارهها نيز براى تفكر و ادراك مهماند و تأثير اساسى بر روى احساس و و رفتار دارند (ابو الفتحى، (وسب). از طرفى كلاركك و فربورن (•^شا) و هميبرگك و بيكر (Y...Y)

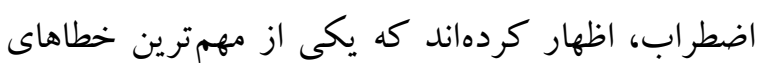
شناختى، ترس از ارزيابى منفى توسط ديخران است. ترس إس از ارزيابى منفى، در ايجاد و حفظ اضطر اب غيرمنطقى و

${ }^{1}$ - Halichin 
آورى شده در بخش آمار توصيفى و آمار استنباطى با

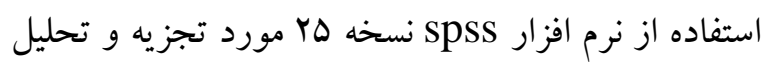

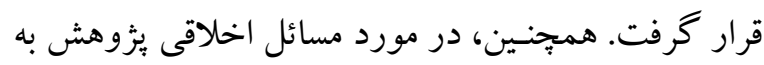

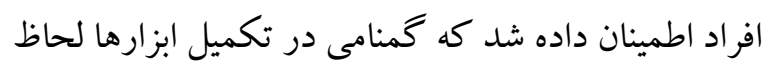
شده است و رازدارى و محرمانه بودن اطلاعات حفظ مى شود.

ابزار ابزارهاى جمع آورى داده ها در ادامه به تفصيل آمده

يرسشنامه طرحوارههاى ناسازكار اوليه يانتك: اين

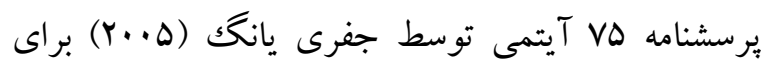

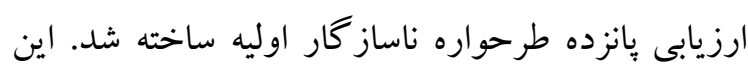
يانزده طرحواره عبارتاند از: ( (- محروميت هيجانى r-

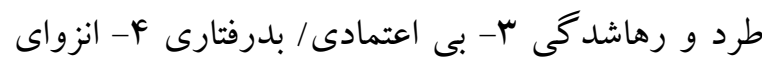

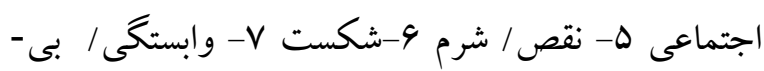
كفايتى ^- آسيب بذيرى نسبت به ضرر يا بيمارى ه-

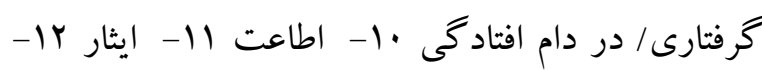
بازدارى هيجانى سا - معيارهاى نا منعطف f أ- استحقاق ها- خويشتن دارى و خود انضباطى ناكافى). اين ها طرحواره در درون ه حوزه مطابق با حوزه تحولى اوليه

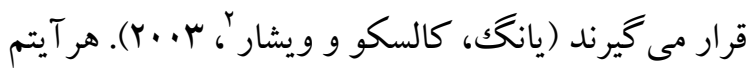
هر آيتم بر روى يكك مقياس 4 درجهاى نمره گذارى مى شود. در اين برسشنامه هر ه سؤال يكك طرحواره را مى-

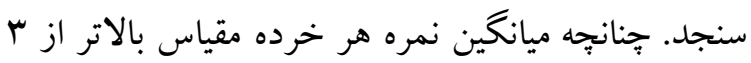
باشد آن طرحواره ناكارآمد خواهد بود (نورداهى،

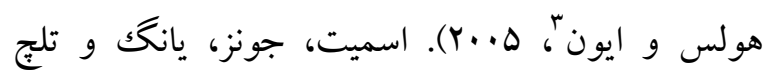
(1990) در مطالعه اى نشان داد كه براى هر طرحواره
آمدن عزت نفس سبب تشديد اضطراب مىشود

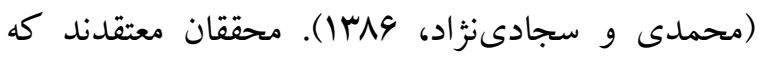
مبتلايان به اضطراب امتحان، ترس اجتماعى از ارزيابى منفى از سوى ديخران دارند و به جاى تمركز بر امتحان ممكن است به ارزيابى منفى ديخران از خود متمركز شوند و همين امر منجر به كاهش عملكرد آنها مى گردد (وانگك، هسو، گيو و لانگگ' اضطراب امتحان نه تنها مىتواند بر كليت برنامههاى مطالعاتى فراكيران تأثير گذارد، بلكه توسعه فردى آنان را نيز محدود مى سازد. در نهايت امر، اين يديده، بر نظام

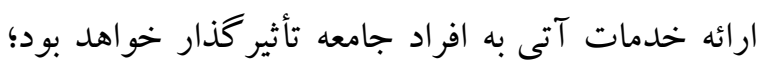
بنابراين، هدف بُزوهش حاضر پِاسخ به اين سؤال است

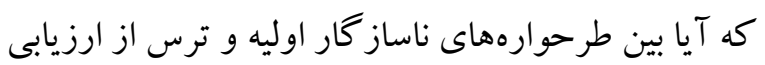
منفى در دانش آموزان مبتلا به اضطراب امتحان رابطه وجود دارد يا خير؟

\section{روش} مطالعه حاضر توصيفى از نوع همبستگى است. جامعه آمارى اين يثزوهش شامل كليه دانش آموزانى مبتلا به اضطراب امتحان مراجعه كننده به مركز مشاوره آموزش و يرورش شهر قاينات در سال V9 بودند كه تعداد ... نفر به صورت هدفمند به عنوان نمونه انتخاب شدند. معيارهاى ورود به مطالعه تمايل به شركت در بزخوهش، دامنه سنى بين 19 تا 19 سال، عدم ابتلا به اختلالات روانى و جسمانى حاد، مبتلا بودن به اضطراب امتحان بر اساس نظر روانشناس و برسشنامه اضطراب امتحان؛ و و ورابى معيار خروج از مطالعه هم شامل دانش آموزانى مى شود

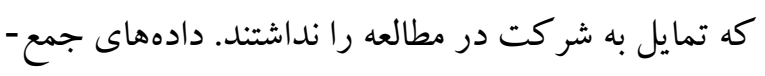

\footnotetext{
1. Wang, Hsu, Chiu \& Liang
} 
ويزگ هاى روانسنجى ايـن مقيـاس را در دانشجويان

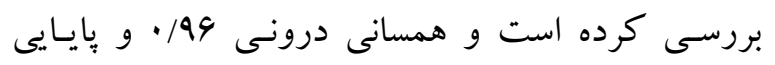

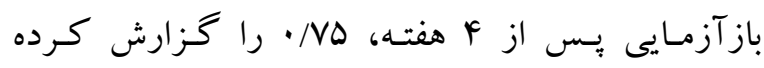

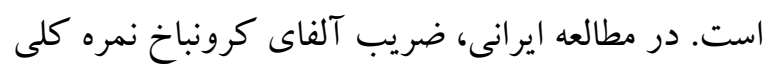

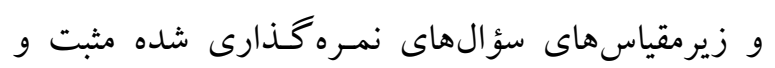

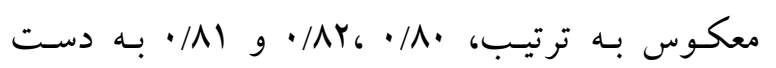

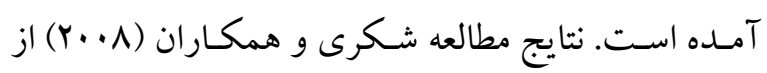
روايسى سـازه مقيـاس كوتاه، ترس از ارزيابى منفى، به طور تجربى حمايت كرد. در تحقيتق حاضس، آلفـاى كرونبـاخ بـراى كـل آزمون AV/ • به دست آمد (تو كلى و

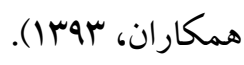

\section{يافتهها} مطالعه حاضر را ... نفر از دانش آموزان كه لها نفر بسر

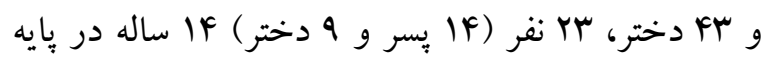
دهم، ·F نفر ( آY يسر و VI دختر) ها ساله در بايه دهم و

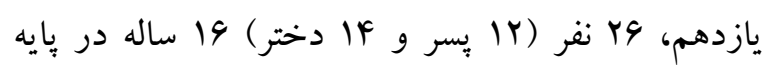

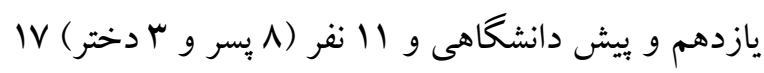
ساله در يايه بيش دانشگاهى حضور داشتند، تشكيل داد. در اين مطالعه آمارهاى توصيفى مربوط به طرحواره هاى ناساز گار اوليه و ترس از ارزيابى در جدول ا شرح داده
ناساز گار اوليه ضريب آلفايى از ^ץ/· (طرحواره خود

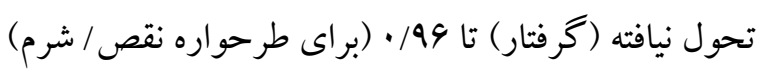
به دست آمد و ضريب باز آزمايى در جمعيت غير بالينى بين •ه/· تا AY/· · بود. خرده مقياسهاى اوليه پيايايى آزمون- بازآزمون و ثبات درونى بالايى نشان دادند. فاتحى همسانى درونى يرسشنامه را از طريق محاسبه

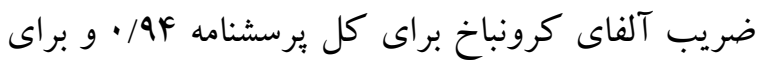
ينج حوزه به اين شرح به دست آمد: بريدكى و طرد

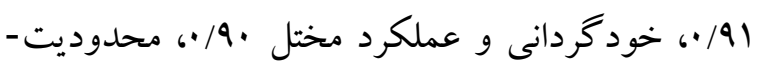

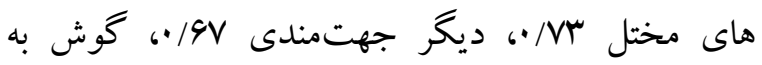

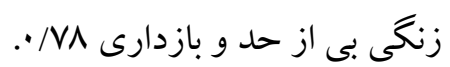

فرم كوتاه مقيـس تــرس از ارزيـابع منفسى: اين مقياس توسط ليرى (r/911) ساخته شده است داراى r ا ماده است و براى توصيف باورهاى ترس آور و نغران كننده طراحى شده است. ياسخدهنده وضعيت خود را در هـر

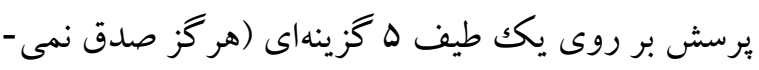

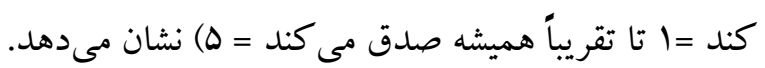

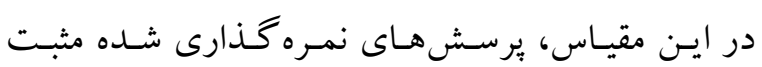

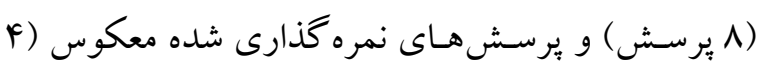
برسش)، وجود ترس و نكرانى را توصيف مى كنتـد و نمـرهـاى بـالا نشان مىدهند كه فرد سطوح بالاى اضطراب و تـرس را تجربـه مى كند. ليـرى (س (19)

\section{جدول آ آمارههاى توصيفى مربوط به متغير هاى كمى ثخوهش}

\begin{tabular}{|c|c|c|c|c|c|}
\hline كشيدكى & جولكى & 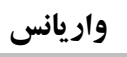 & انحراف معيار & ميانگين & \\
\hline$-\cdot / Y F Y$ & $\cdot /$ TIr & $\cdot / Y q V$ & .1019 & $r \& \& / \Delta V$ & طرحواره هاى ناساز كار اوليه \\
\hline$-\cdot / \& \vee \wedge$ & 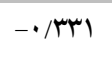 & $\cdot / 4 \cdot 1$ & $.9 \pi \pi$ & KY/AT & ترس از ارزيابى منفى \\
\hline
\end{tabular}

متوسط به بالاى آن را نشان مىدهد. مقدار جولخى اين متغير برابر rاس// است؛ جهون مقدار آن مثبت است جهت
در جدول ا ميانگين نمرهى ياسخگگ يان در مورد متغير طرحواره هاى ناساز گار اوليه برابر YF\&/DV است كه ميزان 
جهت جولگَى به سمت جِ است و اين مطلب يعنى نمرهى بيشتر باسخگ يان در اين متغير، از مقدار ميانكين بيشتر است. براى بررسى توزيع نرمال داده ها از آزمون

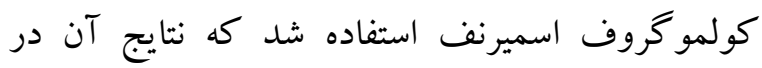
جدول r آورده شده است.
جولكى به سمت راست است و اين مطلب يعنى نمرهى بيشتر پياسخگويان در اين متغير، از مقدار ميانگين كمتر

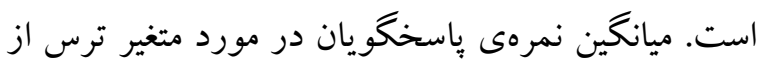
ارزيابى منفى برابر FY/AY/R است كه ميزان متوسط به بالاى

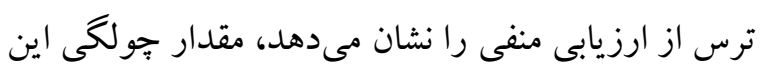
متغير برابر اسس/•- است ؛ جهون مقدار آن منفى است

\begin{tabular}{|c|c|c|}
\hline وكروف اسميرنف & كمك آزمون " & جدول † بررسى فرضيه نرمالين \\
\hline سطح معنادارى & آماره آزمون & \\
\hline$\cdot / \Delta T V$ &.$/ 91 r$ & طرحوارههاى ناساز كار اوليه \\
\hline$\cdot / \mathrm{NH \Lambda}$ & .1944 & ترس از ارزيابى منفى \\
\hline
\end{tabular}

مشاهدات مربوط به متغيرها، نرمال هستند. در ادامه به ضرايب رگرسيون به دست آمده در جدول م اشاره

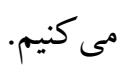

نتايج آزمون كولمو گروف-اسميرنف حاكى از آن است كه سطح معنادارى براى متغيرها، بيش از هـ/• است لذا

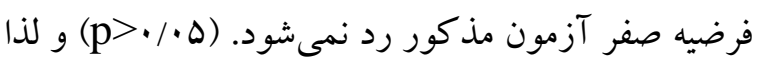

\begin{tabular}{|c|c|c|c|c|c|c|c|c|}
\hline SIG & $\mathbf{F}$ & $\mathbf{R}^{2}$ & $\mathbf{R}$ & SIG & $\mathbf{T}$ & ميزان تأثير & ضرايب & مدل رترسيون \\
\hline \multirow[t]{2}{*}{$\cdot / \cdot \cdot 1$} & IT/NTT &.$/ 110$ & . & $\cdot / \cdots$ & Q/Fr. & - & $1 \Delta Y / I V F$ & مقدار ثابت \\
\hline & & & &.$/ . .1$ & $-r / 09 \Lambda$ & $--(r / q$ & . TrY & طرحواره هاى ناساز گار اوليه \\
\hline
\end{tabular}

بمث

يزوهش حاضر با هدف بررسى رابطه طرحواره هاى ناساز گار اوليه و ترس از ارزيابى منفى در دانش آموزان مبتلا به اضطراب امتحان بود. نتايج مطالعه نشان داد كه

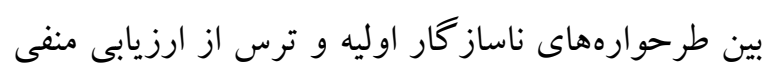
در دانش آموزان مبتلا به اضطراب امتحان رابطه وجود دارد (ه•/p>). در تحليل رگرسيون ضريب تأثير ترس از ارزيابى منفى برابر هسب/، و مثبت است و معناى آن اين

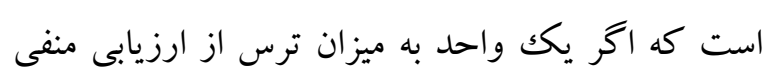

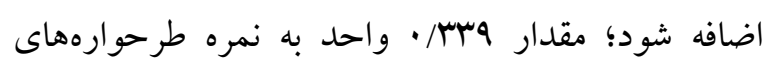

مطابق نتايج به دست آمده، ضريب رگرسيون اين مدل

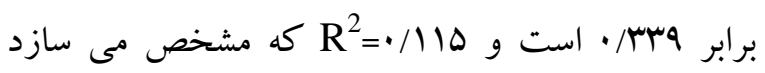
11/1/ درصد داده ها را بوشش مى دهد؛ سطح معنى دارى F=./.·l

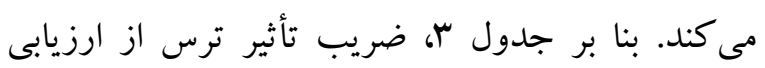

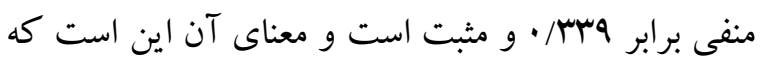
اكر يكك واحد به ميزان ترس از ارزيابى منفى اضافه شود؛ مقدار هسب/ • واحد به نمره طرحوارههاى ناساز كار اوليه اضافه مىشود. 
ناساز گار اوليه در شكل گيرى و گسترش بسيارى از مشكلات روانشناختى همجيون اختلالهاى شخصيت،

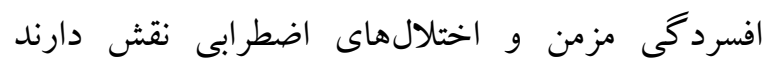

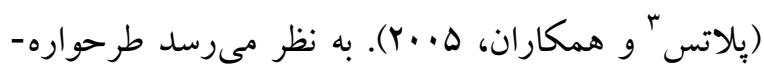
هايى كه با وابستخى و نقص مر تبط هستند، بيشتر در ميان افراد افسرده و طرحوارههايى كه مرتبط با حوزه

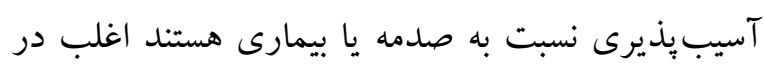
افرادى كه اضطراب دارند وجود داشته باشد (يانك؛، . (Y.M يانكُ بر اين باور است كه طرحوارههاى ناساز كار در

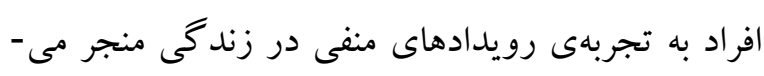

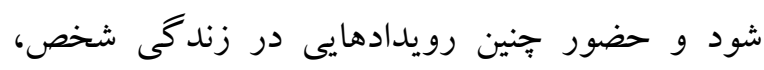

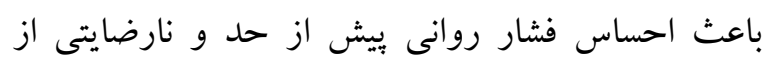

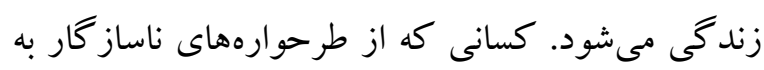

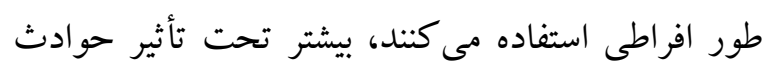

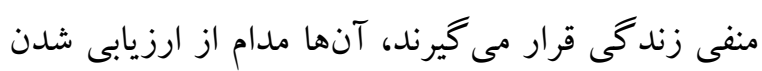

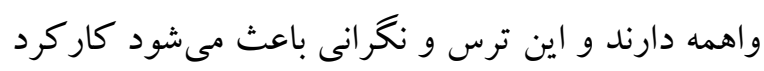

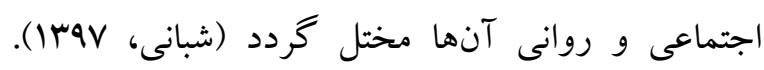

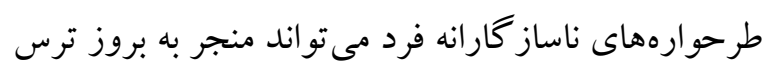

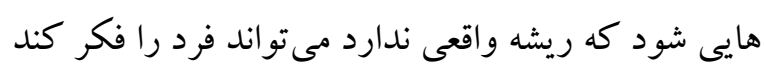

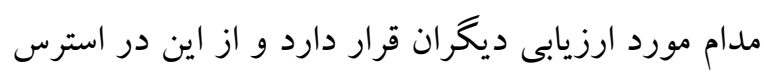

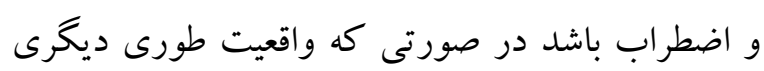

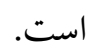

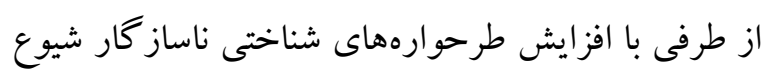

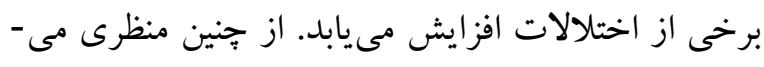

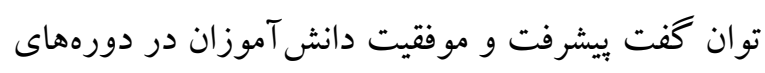
تحصيلى تا حدود زيادى به طر حوارههاى شناختى بستخى دونى

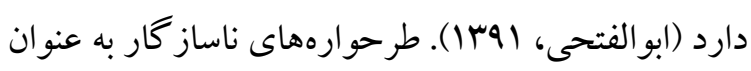

3. Platts
ناساز كار اوليه اضافه مىشود. نتايج اين فرضيه با نتايج

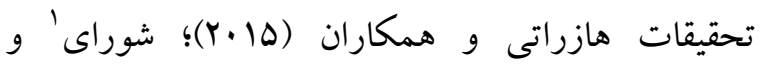

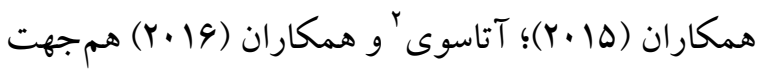
و همسو است. فيضى و كاكا برايى (سوجسا) نيز نشان دادند كه ترس از ارزيابى منفى بهترين ويي بينى كنئد اضطراب است و اين مىتواند از طرحوارههاى فرد نشات

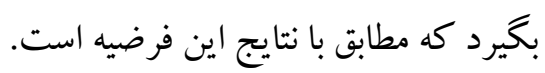

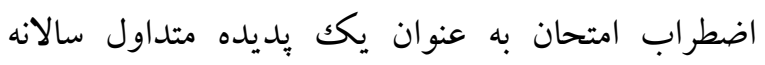

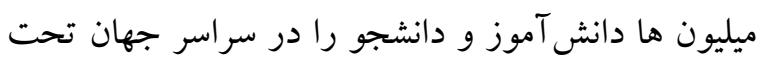

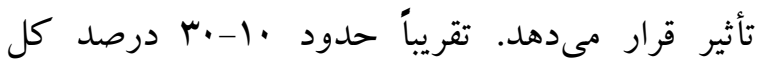

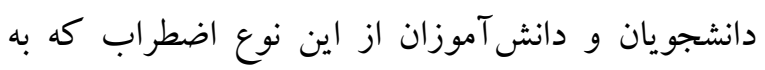
اضطراب امتحان ناتوان كنده نيز شهرت دارد، رنج

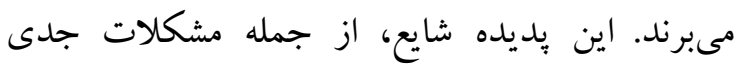

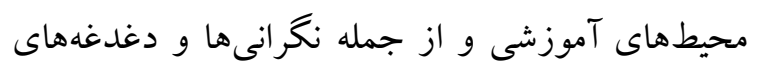

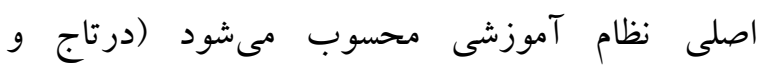

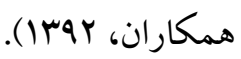

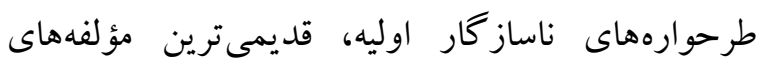

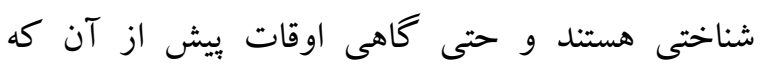

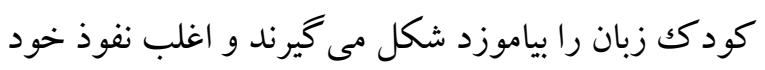
را بر سيستم يردازش دادهها، در زير آستانهى هوشيارى

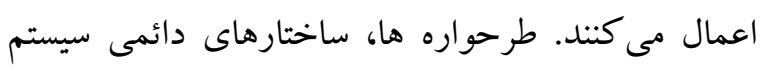

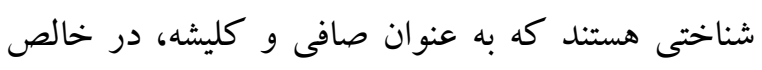
كردن تجربهى فرد از دنيا عمل مى كنند و فرد را در لئر

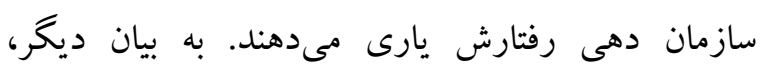

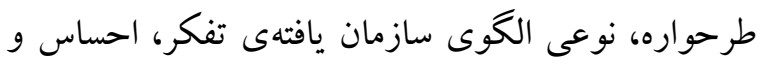
رفتار مبتنى بر مجموعهاى از طرحواره هاست كه راهبرد

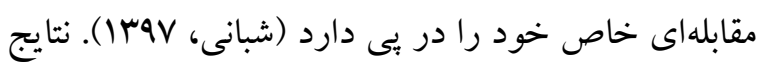
تحقيقات متعدد نشان داده است كه طرحوارههاى

\footnotetext{
1- Shorey

2- Atasoy
} 
مطالعه، امروزه آموزش و برورش بيش از بيش مورد

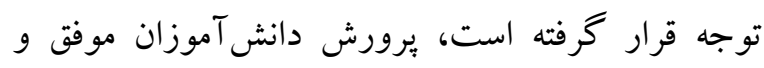
سالم منجر به داشتن جامعهاى سالم تر و موفقتر خواهد

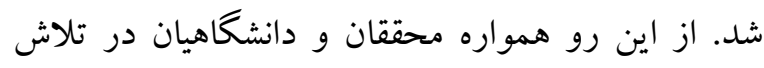
هستند تا بهترين محيط را براى معلمان و دانش آموزان فراهم كرده تا بهترين خروجى و نتيجه حاصل شود. براى معلمان، بهترين فناورىهاى روز، آخرين روشهاى آموزش، مشاورههاى روانشناختى و ساير رويهها اتخاذ مىشوند تا معلمان با بهترين شرايط وارد كلاس درس شوند. در مقابل، دانش آموزان نيز از جنبههاى روانى و عملكردى مورد بررسى قرار مى گيرند تا بهترين روش تدريس متناسب با آنها اتخاذ شود. با توجه به اثرات منفى اضطراب بر عملكرد تحصيلى دانش آموزان، يشنهاد مى گردد كار گاه هايى جهت آشنايى دانش آموزان و والدين آنها با مؤلفهاى بئوهش و اروائه راهكارهاى درمانى جهت كاهش ترس و اضطراب ارائه

\section{سياسگز ارى}

اين مطالعه يكك يثزوهش مستقل كه بدون حمايت سازمانى انجام شده است. از كليه افرادى كه در اين يثزوهش ما را يارى نمودهاند، قدردانى و تشكر مى شود؛؛ مطالعه حاضر در كميته اخلاق در يُزوهش دانشكاه علوم

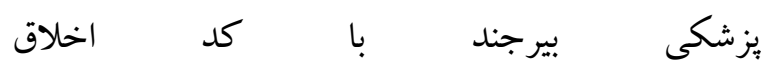
IR.BUMS.REC.1398.344 به ثبت رسيده است.

\section{References}

Abu al-Fitahi M. (2013). Comparison of early maladaptive schemas among students with high test anxiety and normal students. Master's thesis in the field of counseling of the school's
زيرساختهاى شناختى منجر به تشكيل باورهاى غير منطقى مىشود. طرحوارهها داراى مؤلفهاى شناختى، عاطفى و رفتارى هستند هنگامى كه طرحوارههاى

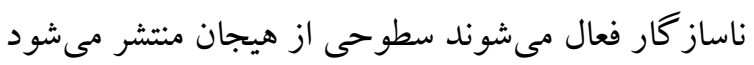
و مستقيم يا غير مستقيم منجر به اشكال مختلفى از

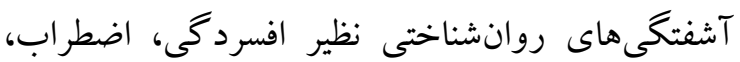
عدم توانايى شغلى، تعارضات بين فردى و مانند آن مى شود. طرحوارههاى ناساز كار مستقيماً منجر به اختلال خاصى نمىشوند؛ اما آسيبيذيرى فرد را براى اين

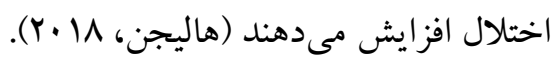
همجِنين وقتى كه فرد تجربه ارزيابى منفى يا مسخره شدن توسط ديخران را داشته باشد، يكك تصوير منفى در او شكل مى گيرد كه همانند يك طر حو اره عمل مى كند. اين مسئله به نوبه خود سبب تفسير منفى رفتار ديخران، رفتار اجتنابى، تلاش براى يوشانيدن و مخفى كردن خود مى -

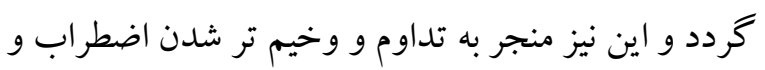
نخر انى شده و شرايط شكل گيرى اختلال روانى را فراهم مىسازد و در نتيجه تأثيرات نامطلوبى بر جنبههاى مختلف زندكى فرد مى گذارد (محمدى و سجادىنزاد، ومشا). لذا از آنجا كه اضطراب امتحان نه تنها مىتواند بر كليت برنامهاى مطالعاتى فراكيران تأثير كذارد، بلكه توسعه فردى آنان را نيز محدود مىسازد. در نهايت امر، اين

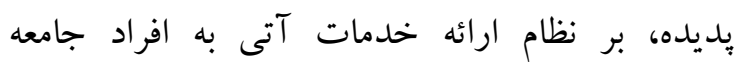
تأثير كذار خو اهد بود.

\section{نتيجه كيرى}

مطالعه حاضر نشان داد كه بين طرحوارههاى ناساز گار اوليه و ترس از ارزيابى منفى در دانش آموزان مبتلا به اضطراب امتحان رابطه وجود دارد و با توجه به يافته هاى 
tendency, Allameh Tabatabai University SemiParadise Campus.

Aramats CA, Moran L, Sands RT. (2003). Gender Differences in Body Image Concems and Depression Amongst Australian Adolescents. The Abstracts of the 38th Conference of the Australian Psychological Society, 163-165.

Atasoy M, KarabulutEO, Yalçinkaya A. (2016). Study on fear of negative evaluation, and social appearance anxiety of university students engaged in futsal. Journal of Physical Education and Sport Management, 7(7), 5055.

Beck T, Kovacs M, Weissman A. (1979). Assessment of suicidal intention: The scale of suicide ideation. Joumal Consult Clinical Psychology, 47,343-352.

Clark D, Farbom C. (2016). Knowledge and Practical Methods of Cognitive Behavioral Therapy. (Translated by Hossein Kaviani). Tehran: Fars Newspaper.

Dortaj F, Mousavi SH, Rezaei P. (2014). Evaluation of test anxiety and its related factors among new students of Hormozgan University of Medical Sciences. Hormozgan Medical Joumal, 17(4), 366-374.

Fatehi Y, Abdokhodai M, Pourghalami F, Nazemi M. (2014). Combining the Effectiveness of Regular Sensitization and Study Skills Training on Students' Anxiety Test. Islamic Azad University, Tonekabon Branch, 4(4), 25-34.

Feizi H, Kakaberi S. (2015). The role of fear of negative evaluation and self-esteem in predicting social anxiety disorder in male adolescents (13-12 years old) in Islamabad, West. The First National Conference on Sustainable Development in Educational Sciences and Psychology, Social and Cultural Studies, 1-8.

Freda I, Gamze A. (2004). Social Phobia Among University Students and its Relation to Selfesteem and Body Image. Canadian Joumal of Psychiatry, 49(9), 630-635.

Ghahvechi-Hosseini F, Fathi-Ashtiani A, Satkin M. (2015). The Effectiveness of Metacognitive
Therapy Compared with Cognitive Therapy in Reducing Test Anxiety, 11(44), 366-357.

Ghasempour A, Fallah A. (2017). Effectiveness of Emotional Regulation Strategies Training for Fear of Positive Evaluation of male Adolescences Suffering from Social Phobia Disorder. Community Health Joumal, 8(4), 59-67.

Halichin R, Whitbume, Susan C. (2018). Psychological Pathology: Clinical Perspectives on DSMRelated Psychiatric Disorders. Translation: Yahya Seyyed Mohammadi. Tehran: Ravan Publication.

Hamid N, Hossein Zadeh A, Kiani Moghaddam R. (2016). Effectiveness of muscle relaxation with positive visualization of success on exam anxiety and fear of negative evaluation. Joumal of Clinical Psychology, 6(2), 41-50.

Hazrati L, Ghorban Shiroudi Sh. (2015). Comparison of Early Maladaptive Schemas in Depressed, Anxious, Obsessed and Normal Individuals. Joumal of Applied Environmental and Biological Sciences, 5(5), 148-153.

Heimberg RG, Becker RE. (2002). Cognitivebehavioral group therapy for social phobia: Basic mechanisms and clinical strategies. New York: Guilford Press.

Izadinia M, Ghanbari N. (2018). The role of self-esteem and coping skills with student anxiety test. Scientific Journal of Psychology of Education Sciences and Social Sciences, 2(23), 64-72.

Kent G. (2000). Understanding the Experiences of People with Disfigurements: An Integration of Four Models of Social and Psychological Functioning. Psychology, Health \& Medicine, 5(2), 117-129.

Kumar S, Singh J. (2013). Emotional intelligence and adjustment among visually impaired and sighted school students. Asian $\mathbf{J}$ Multidimension Res, 2(8), 1-8.

Leary RM. (1983). A brief version of the fear of negative evaluation scale, Personality and Social Psychology Bulletin, 9, 371-375.

Lepine JP, Pelissolo A. (2000). Why Take Social Anxiety Disorder Seriously? Depression and Anxiety, 11, 87-92. 
Markham A, Thompson T, Blowing A. (2005). Determinants of Body- Image Shame. Personality and Individual Differences, 38, 1529-1541.

Moeni S. (2013). Relationship between Scheme and Noncompatible coping strategies with exam anxiety. Master's Degree in Educational Psychology, Islamic Azad University, Tehran Central Branch, Faculty of Psychology and Social Sciences.

Mohammadi N, Sajjadinejad MS. (2008). The relationship of concem to the body image, the fear of negative evaluation and self-esteem with social anxiety. Joumal of Psychology, Tabriz University, 2(5),56-70.

Mojtabai M, Lashkari A. (2009). Relationship between the fear of negative evaluation and trait anxiety with students' shyness. Thought and Behavior, 5(2), 1-12.

Naimi M, Maktabi GH, Emidian Mo. (2018). The Effect of Emotional Intelligence Training on Bullying, Social Competence and Emotional Intelligence Components of Male Primary School Students (Second Year) in Shadegan. Magazine of Principles of Mental Health, 19(3), 41-136.

Nordahl H. M, Holth H, Ion A. (2005). Early Maladaptive schemas in Patient with or without personality disorders clinical. psychology and psycho therapy, 12, 142-149.

Platts H, Mason O, Tyson M. (2005). Early maladaptive schemas and adult attachment in a UK clinical sample. Psychology and Psychotherapy: Theory Research and Practice, 78,549-564.

Schmidt NB, Joiner TE, Young JE, Telch MJ. (1995).

The schema questionnaire: Investigation of psychometric properties and the hierarchical structure of a measure of maladaptive schemas. Cognitive Therapy and Research, 19,295-321.

Shabani J. (2018). Expectant Anxiety Test Based on Early Maladaptive Schemes in Secondary Secondary School Students in Gorgan. Psychology and Psychiatry Cognition, 4(2),47-57.
Sharifaskari Z, Fathiashtiani A, Alipour A, Safarinia M. (2013). The Psychophysical Changes Related to Exam Anxiety in Qualitative-Descriptive Evaluation of Elementary School Students. Quarterly Joumal of Health Psychology, 1(4), 42-55.

Shokri O, Geravand F, Naghsh Z, Ali Tarkhan R, Paeezi M. (2008). The Psychometric Properties of the Brief Fear of Negative Evaluation Scale. IJPCP, 14(3), 316-325.

Shorey RC, Elmquist J, Anderson S, Stuart GL. (2015). The Relation between Early Maladaptive Schemas, Depression, and Generalized Anxiety among Adults Seeking Residential Treatment for Substance Use Disorders. J Psychoactive Drugs, 47(3), 230-238.

Stankov G. (2010). Unforgiving Confucian culture: A breeding ground for high academicachievement, test anxiety and selfdoubt? Leaming and Individual Differences.

Tavakoli NF, Farokhi N. (2015). Relationship between attachment styles and fear of negative evaluation with Internet addiction in students. Quarterly Joumal of Information and Communication in Educational Sciences, 5(2), 61-77.

Trifoni A, Shahini M. (2011). How does exam Anxiety affect the performance of University Students? Mediterranean Joumal of Social Sciences,12, 93-100.

Wang WT, Hsu WY, Chiu YC, Liang CW. (2012). The hierarchical model of social interaction anxiety and depression: The critical roles of fears of evaluation. J Anxiety Disord, 26(1), 215-24.

Watson D, Friend R. (1996). Measurement of social evaluative anxiety. Joumal of Consulting and Clinical Psychology, 33, 448-457.

Yang J, Ecolexco J, Vishar M. (2018). Scheme therapy. Translation: Hamid Pour and Andozes. Tehran: Arjomand Publication.

Yee H. (2013). The moderating role of emotional stability in the relationship between exposure to violence and anxiety and depression. Pers Individ Diff, 55, 634-9. 
الهه آهنخرى و همكاران

Young JE, \& Brown G. (2005). Young Schema Questionnaire-Short Form; Version 3 (YSQS3, YSQ) [Database record]. APA PsycTests.

Young JE, Klosko JS, Weishaar ME. (2008). Schema therapy: A practitioner's guide. New York: The Guilford Press, 23-64. 